\title{
Efficacy of long-term tenofovir disoproxil fuma- rate therapy in chronic hepatitis B patients with partial virologic response in real practice
}

\author{
Jeong Eun Song, Chang Hyeong Lee, and Byung Seok Kim
}

Department of Internal Medicine, Daegu Catholic University School of Medicine, Daegu, Korea

Received: January 24, 2019

Revised : February 15, 2019

Accepted: February 18, 2019

\section{Correspondence to}

Byung Seok Kim, M.D.

Department of Internal Medicine,

Daegu Catholic University School of

Medicine, 33 Duryugongwon-ro 17-

gil, Nam-gu, Daegu 42472, Korea

Tel: $+82-53-650-4090$

Fax: +82-53-656-3281

E-mail: kbs9225@cu.ac.kr

https://orcid.org/0000-0002-4318-4570
Background/Aims: The optimal management of chronic hepatitis B (CHB) patients with partial virologic response (PVR) to tenofovir disoproxil fumarate (TDF) remains unclear. We aimed to evaluate the long-term efficacy of prolonged TDF therapy in treatment-naïve CHB patients with PVR to TDF therapy in real practice.

Methods: We retrospectively investigated the efficacy of prolonged TDF therapy in treatment-naïve CHB patients with PVR to TDF. PVR was defined as a decrease in serum hepatitis B virus (HBV) DNA over $2 \log _{10} \mathrm{IU} / \mathrm{mL}$ from baseline, with detectable HBV DNA by real-time polymerase chain reaction at week 48.

Results: We included 232 patients who underwent TDF therapy for over 48 weeks. Forty-two patients (18.1\%) showed PVR. In multivariate analysis, hepatitis B e antigen (HBeAg) positivity, and high levels of serum HBV DNA at baseline and week 12 were independent predictive factors for PVR during TDF therapy. Out of 42 patients with PVR, 39 (92.9\%) achieved virologic response (VR) during continuous TDF treatment; the cumulative VR rates at 24,36 , and 48 months were $79.8 \%, 88.2 \%$, and 95.6\%, respectively. With an additional 12 months of therapy, VR was achieved in 28/31 (90.3\%) patients with HBV DNA < $100 \mathrm{IU} / \mathrm{mL}$, compared to $5 / 11$ (45.5\%) patients with $\mathrm{HBV} \mathrm{DNA} \geq 100 \mathrm{IU} / \mathrm{mL}$, at week 48.

Conclusions: The vast majority of patients achieved VR through prolonged TDF therapy, thus TDF treatment can be maintained in nucleos(t)ide-naïve patients with PVR at week 48, especially in those with low viremia.

Keywords: Hepatitis B, chronic; Tenofovir; Partial virologic response; Real practice

\section{INTRODUCTION}

Chronic hepatitis $\mathrm{B}(\mathrm{CHB})$ is a major health problem worldwide and a leading cause of liver cirrhosis and hepatocellular carcinoma (HCC). The primary aim of antiviral therapy for CHB is long-term suppression of viral replication, which prevents disease progression, and consequently HCC development [1,2]. During long-term antiviral therapy, drug resistance and incomplete viral suppression correlate with increased risk of adverse liver events, including progression to cirrhosis, HCC, and death [3]. Several studies have reported that early viral suppression is important to reduce the risk of resistance to nucleos(t)ide analogues (NAs) [4,5]. Partial virologic re- 
sponse (PVR) is defined as a decrease in hepatitis B virus (HBV) DNA of more than $1 \log _{10} I U / m L$ or $2 \log _{10} I U /$ $\mathrm{mL}$, but still detectable by real-time polymerase chain reaction (PCR) at week 24, according to previous CHB practice guidelines [6-8]. PVR is related to increased risk of antiviral resistance, treatment failure and progression of liver disease, especially in NAs with low genetic barrier to resistance, such as lamivudine (LAM), telbivudine (LdT), or adefovir (ADV) [9,10]. Therefore, early treatment modification, including switching to more potent NAs should be recommended in patients with PVR to these antiviral agents.

Currently, the main treatment option for CHB patients is a potent NA with high barrier to resistance, such as entecavir (ETV) and tenofovir disoproxil fumarate (TDF), which show predictable long-term antiviral efficacy [11]. Compared to LAM or ADV in treatment-naïve CHB patients, ETV and TDF showed superior virologic and biochemical responses. Furthermore, several studies reported that development of antiviral resistance was rare $(<1 \%)$ in ETV and did not occur in TDF after longterm treatment [11]. In case of antiviral therapy with drugs of high potency and lower rate of resistance, determination of PVR has been recommended at week 48 $[2,11]$. In clinical trials for treatment-naïve CHB patients with ETV monotherapy, $10 \%$ to $30 \%$ of patients show persistent detectable HBV DNA at week 48 [12,13]. However, recent studies have reported that continuous treatment using ETV lead to consistently increasing virologic response (VR) rate until after 1 to 4 years [14-16]. These results support the idea that treatment adaptation is not necessary in patients treated with high potent NAs with high genetic barriers including ETV, unlike less potent NAs with low barrier to resistance [11].

However, there are limited data regarding the VR to prolonged TDF therapy in patients with PVR. It is thus uncertain whether adjustment of antiviral therapy is required for patients treated with TDF. Therefore, the objectives of this study were to evaluate the efficacy of TDF in clinical practice for NAs-naïve CHB patients during a long-term period, to investigate baseline and on-treatment factors predicting PVR to TDF therapy, and to assess whether PVR affects long-term clinical outcomes of TDF treatment.

\section{METHODS}

\section{Patients}

CHB patients, treated with $300 \mathrm{mg}$ TDF daily between January 2013 and March 2016 at Daegu Catholic University Hospital, were identified using the electronic medical records. The following inclusion criteria were applied:(1) treatment-naïve CHB patients, (2) over 18 years old, and (3) over 12 months TDF treatment. Patients were excluded if they had preemptive treatment during chemotherapy, or antibodies against hepatitis $\mathrm{C}$ virus, or human immunodeficiency virus or HCC, or poor compliance before achieving complete virologic response (CVR).

All patients were assessed at baseline and every 3 to 6 months during TDF therapy, including tolerability of medication, blood chemistry, HBV DNA titer, hepatitis $\mathrm{B}$ e antigen (HBeAg), and antibody against $\mathrm{HBeAg}$ (anti-HBe). Patients underwent HCC surveillance every 6 months: (1) abdominal ultrasound, (2) measurements of serum $\alpha$-fetoprotein. During baseline assessment, we diagnosed cirrhosis clinically, based on imaging findings (abdominal ultrasonography or computed tomography, or magnetic resonance imaging) and compatible clinical features.

\section{Definitions and study endpoints}

The level of HBV DNA was quantified using real-time PCR (COBAS Taq-Man HBV quantitative test, Roche Molecular systems Inc., Branchburg, NJ, USA; detection limit $=20 \mathrm{IU} / \mathrm{mL})$. Hepatitis B s antigen ( $\mathrm{HBsAg}$ ), $\mathrm{HBeAg}$, antibodies against $\mathrm{HBsAg}$, and anti-HBe were assayed using electrochemiluminescence immunoassay (Roche Diagnostics, Mannheim, Germany).

CVR was defined as undetectable level of HBV DNA $(<20 \mathrm{IU} / \mathrm{mL})$ at week 48 and VR was defined as undetectable serum HBV DNA during TDF treatment. PVR was defined as a decrease in HBV DNA of more than $2 \log _{10} I U / m L$, but still detectable by real-time PCR at week 48 in patients with good compliance [8]. Virologic breakthrough (VBT) was defined as an increase in serum HBV DNA of more than $1 \log _{10} I U / \mathrm{mL}$ compared to nadir during continued treatment [8]. Definition of alanine aminotransferase (ALT) normalization differed according to sex: $<30 \mathrm{IU} / \mathrm{L}$ for males and $<19 \mathrm{IU} / \mathrm{L}$ for females. 
299 Patients were consecutively treated with TDF for CHB between January 2013 and March 2016

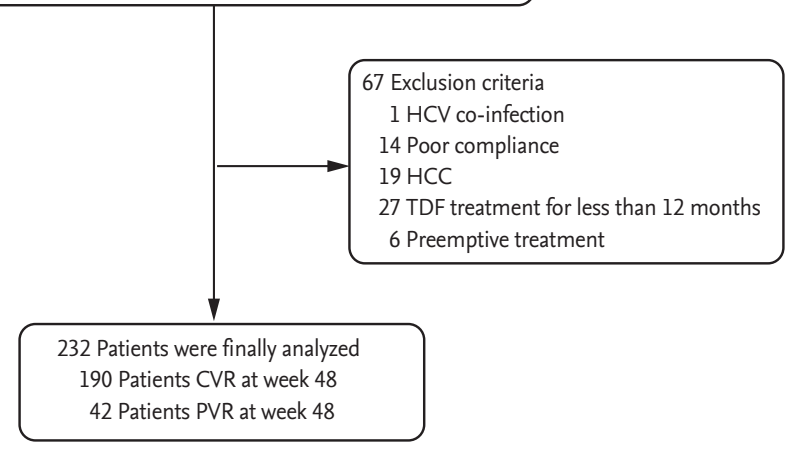

Figure 1. Flow diagram of the selected study population. TDF, tenofovir disoproxil fumarate; $\mathrm{CHB}$, chronic hepatitis $\mathrm{B}$; HCV, hepatitis C virus; HCC, hepatocellular carcinoma; CVR, complete virologic response; PVR, partial virologic response.

\section{Statistical analysis}

SPSS version 21.0 was used for all statistical analysis (IBM Co., Armonk, NY, USA). To compare categorical variables, we applied the chi-square or Fisher's exact tests. Continuous data were compared between the groups using Student's $t$ test. Serum HBV DNA levels were logarithmically converted for analysis. Kaplan-Meyer statistics and the log-rank test were performed to compare the cumulative rate of VR. Univariate and multivariate analyses to identify clinical factors predicting PVR were performed using logistic regression. To determine the optimal cut-off values for HBV DNA level predicting PVR, median HBV DNA levels were calculated and validated by area under receiver operating characteristic (AUROC) curve. Statistical significance was accepted for $p<0.05$.

\section{Ethics statement}

This study protocol was reviewed and approved by the Institutional Review Board (IRB) of Daegu Catholic University Hospital (CR-18-166). Documentation of informed consent was waived by the IRB because this study was a retrospective analysis of existing clinical data.

\section{RESULTS}

\section{Baseline characteristics of patients}

A total of 299 treatment-naïve CHB patients were administered TDF at Daegu Catholic University Hospital from January 2013 to March 2016. Among them, 67 patients were excluded; one patient due to HCV co-infection, 14 patients due to poor compliance before CVR, 19 patients due to HCC, 27 patients due to short treatment period ( $<12$ months), and six patients because of preemptive treatment. The remaining 232 patients were included in the analysis (Fig. 1). The median treatment duration was 40.4 months (range, 12.3 to 65.1). Baseline characteristics and laboratory data are summarized in Table 1. The mean age of patients was $51.3 \pm 11.3$ years, and more than half were male (55.2\%). One hundred and twelve patients (48.3\%) had liver cirrhosis and 125 patients (53.9\%) were HBeAg-positive. Two hundred and twelve patients (91.4\%) had abnormal ALT levels. The mean baseline serum ALT level was 245.3 $\pm 445.6 \mathrm{IU} / \mathrm{L}$ and the serum HBV DNA level was $6.30 \pm 1.42 \log _{10} \mathrm{IU} / \mathrm{mL}$.

\section{Clinical outcomes of TDF therapy at week 48}

Among the 232 patients, 190 (81.9\%) achieved CVR at week 48. A total 42 patients (18.1\%) showed PVR at week 48 even though drug compliance was optimal (Table 2). HBeAg-negative patients showed a significantly higher rate of CVR compared with HBeAg-positive patients (95.3\% vs. 70.4\%, $p<0.001$ ), and a significantly lower rate of PVR ( $4.7 \%$ vs. $29.6 \%, p<0.001)$. Overall mean reduction of HBV DNA from baseline was $6.30 \pm 1.42 \log _{10} \mathrm{IU} / \mathrm{mL}$. The degree of HBV DNA reduction was significantly greater in HBeAg-positive than in HBeAg-negative patients $\left(6.99 \pm 1.15 \log _{10} \mathrm{IU} / \mathrm{mL}\right.$ vs. $5.50 \pm 1.28 \log _{10} \mathrm{IU} / \mathrm{mL}$, $p<0.001)$. The proportion of patients with normal ALT was $70.6 \%$ at week 48 and it was not significantly different between $\mathrm{HBeAg}$-positive and HBeAg-negative patients (67.2\% vs. $75.3 \%, p=0.226$ ). Out of the $125 \mathrm{HBeAg}$-positive patients, $20(16.0 \%)$ showed HBeAg seroconversion or loss at week 48 .

\section{Factors associated with PVR}

We attempted to determine predictive factors for PVR. Comparison of characteristics between patients with CVR and PVR showed that younger age $(51.9 \pm 11.3 \mathrm{vs}$. $48.2 \pm 10.8, p=0.047)$, HBeAg positivity (46.3\% vs. $88.1 \%$, 
Table 1. Baseline characteristics

\begin{tabular}{|c|c|c|c|c|}
\hline Variable & Total $(n=232)$ & HBeAg-positive $(\mathrm{n}=125)$ & HBeAg-negative $(n=107)$ & $p$ value \\
\hline Age, yr & $51.3 \pm 11.3$ & $48.7 \pm 11.5$ & $54.2 \pm 10.2$ & $<0.001$ \\
\hline Male sex & $128(55.2)$ & $68(51.9)$ & $73(60.8)$ & 0.155 \\
\hline Liver cirrhosis & $112(48.3)$ & $51(38.9)$ & $76(63.3)$ & $<0.001$ \\
\hline Compensated & $106(94.6)$ & $50(98.0)$ & $71(93.4)$ & \\
\hline Decompensated & $6(5 \cdot 4)$ & $1(2.0)$ & $5(6.6)$ & \\
\hline HBV DNA $\left(\log _{10} \mathrm{IU} / \mathrm{mL}\right)$ & $6.30 \pm 1.42$ & $6.99 \pm 1.15$ & $5.50 \pm 1.28$ & $<0.001$ \\
\hline $\mathrm{AST}, \mathrm{IU} / \mathrm{L}$ & $205.6 \pm 409.1$ & $207 \cdot 5 \pm 275 \cdot 0$ & $203 \cdot 3 \pm 525 \cdot 5$ & 0.938 \\
\hline ALT, IU/L & $245 \cdot 3 \pm 445 \cdot 6$ & $251.1 \pm 361.9$ & $238.5 \pm 527.7$ & 0.830 \\
\hline Total bilirubin, mg/dL & $1.81 \pm 3.01$ & $2.06 \pm 3.72$ & $1.51 \pm 1.83$ & 0.144 \\
\hline Serum albumin, g/dL & $3.91 \pm 0.53$ & $3.88 \pm 0.50$ & $3.93 \pm 0.56$ & 0.491 \\
\hline Prothrombin time, INR & $1.18 \pm 0.26$ & $1.16 \pm 0.21$ & $1.20 \pm 0.31$ & 0.223 \\
\hline Platelet, $10^{3} / \mathrm{mm}^{3}$ & $143 \cdot 3 \pm 63.6$ & $152.1 \pm 57.8$ & $133.0 \pm 68.5$ & 0.023 \\
\hline Creatinine, mg/dL & $0.77 \pm 0.17$ & $0.77 \pm 0.17$ & $0.77 \pm 0.17$ & 0.921 \\
\hline
\end{tabular}

Values are presented as mean $\pm \mathrm{SD}$ or number (\%).

HBeAg, hepatitis B e antigen; HBV, hepatitis B virus; AST, aspartate aminotransferase; ALT, alanine aminotransferase; INR, international normalized ratio.

Table 2. Clinical outcomes of tenofovir disoproxil fumarate therapy at week 48

\begin{tabular}{|c|c|c|c|c|}
\hline Variable & Total $(n=232)$ & HBeAg-positive $(\mathrm{n}=125)$ & HBeAg-negative $(\mathrm{n}=107)$ & $p$ value \\
\hline Complete virologic response & $190(81.9)$ & $88(70.4)$ & $102(95 \cdot 3)$ & $<0.001$ \\
\hline Partial virologic response & $42(18.1)$ & $37(29.6)$ & $5(4 \cdot 7)$ & $<0.001$ \\
\hline $\begin{array}{l}\text { Reduction of serum HBV DNA level } \\
\text { from baseline }\left(\log _{10} \mathrm{IU} / \mathrm{mL}\right)\end{array}$ & $6.30 \pm 1.42$ & $6.99 \pm 1.15$ & $5.50 \pm 1.28$ & $<0.001$ \\
\hline HBeAg seroconversion/loss & & $20(16.0)$ & NA & \\
\hline ALT normalization $^{\mathrm{a}}$ & $150 / 212(70.6)$ & $80 / 119(67.2)$ & $70 / 93(75 \cdot 3)$ & 0.226 \\
\hline
\end{tabular}

Values are presented as number (\%) or mean $\pm \mathrm{SD}$.

HBeAg, hepatitis B e antigen; HBV, hepatitis B virus; NA, not applicable; ALT, alanine aminotransferase.

${ }^{a}$ The upper limit of the normal range of alanine aminotransferase was 19 IU/L for females and 30 IU/L for males.

$p<0.001)$, higher serum HBV DNA level at baseline (6.03 $\pm 1.36 \log _{10} \mathrm{IU} / \mathrm{mL}$ vs. $\left.7.56 \pm 0.91 \log _{10} \mathrm{IU} / \mathrm{mL}, p<0.001\right)$ and week $12\left(1.45 \pm 1.17 \log _{10}\right.$ IU/mL vs. $3.22 \pm 0.91 \log _{10}$ $\mathrm{IU} / \mathrm{mL}, p<0.001$ ), and higher rate of detectable serum HBV DNA at week 24 (27.4\% vs. 100\%, p< 0.001$)$ were significantly associated with PVR (Table 3). We analyzed the optimal cut-off levels of HBV DNA at baseline and week 12 for TDF therapy that could maximally predict PVR. The optimal cut-off value of serum HBV DNA level for the prediction of PVR was $6.34 \log _{10} \mathrm{IU} / \mathrm{mL}$ at baseline (AUROC, 0.718; 95\% confidence interval [CI], 0.655 to 0.775; sensitivity, 85.7\%; specificity, 57.9\%), and $1.91 \log _{10} \mathrm{IU} / \mathrm{mL}$ at week 12 (AUROC, 0.776 ; 95\% CI, 0.717 to 0.828 ; sensitivi- ty, 95.2\%; specificity, 60.0\%)(Supplementary Figs. 1 and 2). The clinical factors that are associated with PVR at week 48 were analyzed using univariate and multivariate logistic regression analysis (Table 4). We included age, liver cirrhosis, HBeAg positivity, baseline serum HBV DNA level $\geq 6.34 \log _{10} \mathrm{IU} / \mathrm{mL}$, and HBV DNA at week 12 $\geq 1.91 \log _{10} \mathrm{IU} / \mathrm{mL}$ for analysis. HBeAg positivity (odds ratio [OR], 3.875; 95\% CI, 1.352 to 11.109; $p=0.012$ ), baseline serum HBV DNA level $\geq 6.34 \log _{10} \mathrm{IU} / \mathrm{mL}$ (OR, 3.766; 95\% CI, 1.406 to $10.088 ; p=0.008)$, and HBV DNA at week $12 \geq 1.91 \log _{10} \mathrm{IU} / \mathrm{mL}$ (OR, 16.829; 95\% CI, 3.848 to 73.612 ; $p<0.001)$ were independently associated with PVR. 
Table 3. Comparison of clinical characteristics between patients with complete virologic response and patients with partial virologic response at week 48

\begin{tabular}{|c|c|c|c|}
\hline Variable & $\begin{array}{l}\text { Complete virologic response } \\
\qquad(\mathrm{n}=190)\end{array}$ & $\begin{array}{l}\text { Partial virologic response } \\
\qquad(\mathrm{n}=42)\end{array}$ & $p$ value \\
\hline Age, yr & $51.9 \pm 11.3$ & $48.2 \pm 10.8$ & 0.047 \\
\hline Male sex & $105(55 \cdot 3)$ & $23(54.8)$ & 0.953 \\
\hline Liver cirrhosis & $97(51.1)$ & $15(35 \cdot 7)$ & 0.088 \\
\hline ALT, IU/L & $250.5 \pm 463.7$ & $222.1 \pm 356.4$ & 0.710 \\
\hline HBeAg positivity & $88(46.3)$ & $37(88.1)$ & $<0.001$ \\
\hline Baseline HBV DNA $\left(\log _{10} \mathrm{IU} / \mathrm{mL}\right)$ & $6.03 \pm 1.36$ & $7.56 \pm 0.91$ & $<0.001$ \\
\hline \multicolumn{4}{|l|}{ Treatment outcomes } \\
\hline ALT normalization $^{\mathrm{a}}$ & $150 / 172(87.2)$ & $34 / 40(85.0)$ & 0.795 \\
\hline HBeAg loss & $11 / 88(12.5)$ & $3 / 37(8.1)$ & 0.553 \\
\hline HBeAg seroconversion & $21 / 88(23.9)$ & $3 / 37(8.1)$ & 0.048 \\
\hline HBV DNA at week $12\left(\log _{10} \mathrm{IU} / \mathrm{mL}\right)$ & $1.45 \pm 1.17$ & $3.22 \pm 0.91$ & $<0.001$ \\
\hline Detectable HBV DNA at week 24 & $52(27.4)$ & $42(100)$ & $<0.001$ \\
\hline Virologic response & $190(100)$ & $39(92.9)$ & 0.006 \\
\hline Mean duration of reaching VR, mon & $6.3 \pm 3.4$ & $21.7 \pm 9.0$ & $<0.001$ \\
\hline
\end{tabular}

Values are presented as mean $\pm \mathrm{SD}$ or number (\%).

ALT, alanine aminotransferase; HBeAg, hepatitis B e antigen; HBV, hepatitis B virus; VR, virologic response.

${ }^{\mathrm{a}}$ The upper limit of the normal range of alanine aminotransferase was 19 IU/L for females and 30 IU/L for males.

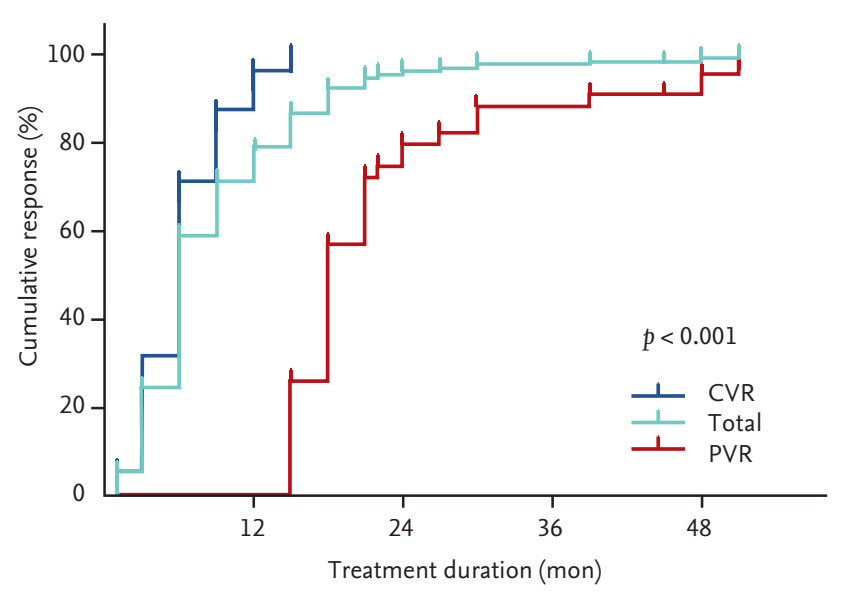

Figure 2. Cumulative rates of virologic response between patients with partial virologic response (PVR) and patients with complete virologic response (CVR) at week 48.

\section{Overall clinical outcomes during long-term continu- ous TDF therapy}

During long-term TDF therapy, 229 patients (98.7\%) achieved VR, irrespective of PVR. The overall cumulative rates of VR at $12,24,36$, and 48 months were $78.9 \%$,
$96.3 \%, 97.9 \%$, and $99.2 \%$, respectively (median time to VR, 6 months; range, 1.0 to 51.0) (Fig. 2). Out of 42 patients with PVR, 39 (92.9\%) achieved VR during continuous TDF treatment. The three patients that did not achieve VR at the end of follow-up included one that was lost to follow-up after 18 months and another two that showed a continuous decline of serum HBV DNA level. The median time to VR in patients with PVR was 18 months (range, 15 to 51). The cumulative rates of VR in patients with PVR at 24,36 , and 48 months were $79.8 \%$, $88.2 \%$, and $95.6 \%$, respectively (Fig. 2). We performed subgroup analysis of VR in patients with PVR during long-term TDF therapy according to the HBV DNA lev$\mathrm{el}$ at week 48 . The cumulative rates of VR at 24,36 and 48 months were significantly higher in patients with HBV DNA level $<100 \mathrm{IU} / \mathrm{mL}$ at week 48 compared to those with HBV DNA level $\geq 100 \mathrm{IU} / \mathrm{mL}$ at week 48 (92.9\%, $96.5 \%$, and $96.5 \%$ vs. $45.5 \%, 65.9 \%$, and $100 \%$, respectively; $p=0.019)$ (Fig. 3).

Overall rates of ALT normalization and HBeAg seroconversion during long-term follow-up were $86.8 \%$ and 19.2\%, respectively. Among patients with PVR, 34 (85.0\%) 
Table 4. Univariate and multivariate logistic regression analysis of clinical factors associated with partial virologic response during tenofovir disoproxil fumarate therapy

\begin{tabular}{|c|c|c|c|}
\hline Variable & Odds ratio & $95 \% \mathrm{CI}$ & $p$ value \\
\hline \multicolumn{4}{|l|}{ Univariate analysis } \\
\hline Age, yr & 0.970 & $0.942-1.000$ & 0.052 \\
\hline Liver cirrhosis & 0.533 & $0.267-1.064$ & 0.075 \\
\hline HBeAg positivity & 8.577 & $3.231-22.722$ & $<0.001$ \\
\hline \multicolumn{4}{|l|}{ Baseline HBV DNA } \\
\hline$<6.34 \log _{10} \mathrm{IU} / \mathrm{mL}$ & Reference & & \\
\hline$\geq 6.34 \log _{10} \mathrm{IU} / \mathrm{mL}$ & 8.250 & $3.318-20.516$ & $<0.001$ \\
\hline \multicolumn{4}{|l|}{ HBV DNA at week 12} \\
\hline$<1.91 \log _{10} \mathrm{IU} / \mathrm{mL}$ & Reference & & \\
\hline$\geq 1.91 \log _{10} \mathrm{IU} / \mathrm{mL}$ & 30.000 & $7.041-127.828$ & $<0.001$ \\
\hline \multicolumn{4}{|l|}{ Multivariate analysis } \\
\hline HBeAg positivity & 3.875 & $1.352-11.109$ & 0.012 \\
\hline Baseline HBV DNA $\geq 6.34 \log _{10} \mathrm{IU} / \mathrm{mL}$ & 3.766 & $1.406-10.088$ & 0.008 \\
\hline HBV DNA at week $12 \geq 1.91 \log _{10} I U / m L$ & 16.829 & $3.848-73.612$ & $<0.001$ \\
\hline
\end{tabular}

CI, confidence interval; HBeAg, hepatitis B e antigen; HBV, hepatitis B virus.

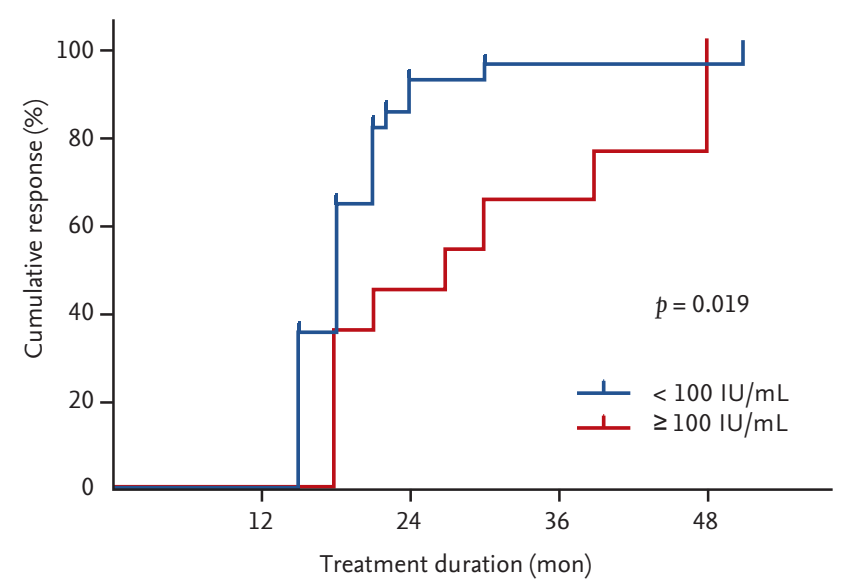

Figure 3. Cumulative rates of virologic response in patients with partial virologic response according to the level of hepatitis B virus DNA at week 48 .

showed ALT normalization and three (8.1\%) achieved HBeAg seroconversion during prolonged TDF therapy. Three patients with HBsAg loss and two patients with HBsAg seroconversion were observed (median duration 21 months; range, 17 to 24). Among three patients with HBsAg loss, one patient with PVR showed HBV reactivation at 12 months after stopping TDF treatment.

Ten patients with CVR (5.3\%) and one patient with PVR (2.4\%) showed VBT after 48 weeks. All VBT in pa- tients with CVR was caused due to skipping medication for more than 2 weeks, and these patients achieved VR within 1 to 6 months after continuous TDF therapy. We performed genetic mutation test in one patient with PVR, who showed VBT at 19 months despite drug compliance. There was no genotypic resistance to TDF according to restriction fragment mass polymorphism, and the patient achieved VR at 51 months after prolonged TDF therapy.

In our study, deterioration of renal function was not observed in any patient during the entire treatment period. After a median 42.8 months of treatment, six out of the 42 patients with PVR showed mild hypophosphatemia (serum phosphorus level $<2.7 \mathrm{mg} / \mathrm{dL}$ ) while their serum creatinine levels did not exceed $0.5 \mathrm{mg} / \mathrm{dL}$. During long-term TDF therapy, the most common liver-related events were HCC $(n=16)$, followed by variceal bleeding $(n=3)$, and ascites $(n=1)$. All events of variceal bleeding and ascites were developed within 12 months after starting TDF treatment. Sixteen patients developed HCC during a median follow-up period of 22 months (range, 6 to 49). One patient died from hepatic failure due to reactivation of HBV after stopping TDF treatment. There was no significant difference in any liver-related events between patients with and without PVR. 


\section{DISCUSSION}

During treatment with oral antiviral agents, persistent viral replication has been related to adverse treatment outcomes $[9,10]$. Thus, it is important to check PVR at an adequate time point according to the antiviral potency and genetic barrier to resistance. Early treatment adaptation was recommended to prevent treatment failure and development of resistance in patients with PVR receiving LAM, LdT, or ADV [7]. However, for patients with ETV or TDF therapy showing PVR, recommendations in international guidelines are not uniform as to whether treatment should be continued or switched to another drug $[2,11,17]$. Currently, several studies have reported that the vast majority of treatment-naïve patients with PVR under ETV therapy achieved further VR during prolonged ETV therapy without treatment adaptation [14-16]. In contrast, there are very limited data for patients with PVR to TDF and it is still uncertain whether TDF therapy is modified or continued in patients with PVR.

In this study, 42 out of 232 patients treated with TDF failed to achieve CVR at week 48. Among patients with PVR, 39 patients (92.9\%) achieved further VR without treatment modification during a median period of 18 months (range, 15 to 51). This result is in accordance with previous studies of ETV therapy demonstrating that the vast majority of patients with PVR showed VR after prolonged ETV treatment [14-16,18]. Furthermore, the rate of VR in patients with PVR was higher in our study than in previous studies of ETV treatment. Thus, our study suggests that treatment should be continued using the same agent without modification in patients with PVR to T'DF.

Several baseline and on-treatment predictors for PVR have been investigated in patients treated with NAs. Previous studies reported that high baseline HBV DNA and $\mathrm{HBeAg}$ positivity, as pretreatment factors, have been associated with PVR [14,16,18-20]. Regarding on-treatment factors during ETV therapy, Kwon et al. [15] suggested that more than $2,000 \mathrm{IU} / \mathrm{mL}$ of serum HBV DNA at week 12 and detectable serum HBV DNA at week 24 were significantly associated with PVR. However, it is unclear which clinical factors can predict PVR in NAs-naïve patients treated with TDF. In this study, we showed that high levels of serum HBV DNA at baseline and week
12, and HBeAg positivity were independent predictive factors for PVR during TDF therapy. The optimal cutoff value of baseline HBV DNA level to predict PVR was $6.34 \log _{10} \mathrm{IU} / \mathrm{mL}$. The rate of PVR in patients with higher baseline HBV DNA $\left(\geq 6.34 \log _{10} \mathrm{IU} / \mathrm{mL}\right)$ and in those with lower baseline HBV DNA $\left(<6.34 \log _{10} \mathrm{IU} / \mathrm{mL}\right)$ were $31.0 \%$ ( 36 of 116 patients) and 5.2\% (six of 116 patients), respectively. HBeAg positivity was another baseline predictive factor for PVR. HBeAg-positive patients showed higher PVR rate than HBeAg-negative patients. In particular, most HBeAg-negative patients (95.3\%) achieved CVR. We also found on-treatment factors to predict PVR during TDF therapy, for example serum HBV DNA level at week 12. Using the optimal cut-off value of HBV DNA level at week $12\left(1.91 \log _{10} \mathrm{IU} / \mathrm{mL}\right)$, the rate of PVR was higher in patients with $\mathrm{HBV}$ DNA level $\geq 1.91 \log _{10} \mathrm{IU} / \mathrm{mL}$ at week 12 than in those with lower level of HBV DNA at week 12 (34.5\% vs. $1.7 \%, p<0.001$ ).

We showed that most patients with PVR at week 48 achieved further VR after prolonged TDF therapy (79.8\% at 24 months, $88.2 \%$ at 36 months, and $95.6 \%$ at 48 months). According to the HBV DNA level at week 48, the cumulative rate of further VR was higher in patients with HBV DNA level < $100 \mathrm{IU} / \mathrm{mL}$ than in those with HBV DNA level $\geq 100 \mathrm{IU} / \mathrm{mL}$ at week 48 . Furthermore, the vast majority of patients ( 28 of 31 patients, 90.3\%) with HBV DNA level $<100 \mathrm{IU} / \mathrm{mL}$ at week 48 achieved VR within an additional 12 months of therapy, compared to patients with HBV DNA level $\geq 100 \mathrm{IU} / \mathrm{mL}$ (five of 11 patients, $45.5 \%)$. Two previous ETV studies also reported that lower viral load at week 48 could predict further VR in patients with PVR [14,15]. However, the level of HBV DNA at week 48 predicting VR was lower in our study than in previous ETV studies (<1,000 IU/mL [14], < $2,000 \mathrm{IU} / \mathrm{mL}$ [15]). In addition, the cumulative rate of further VR in our study was higher than in previous studies of ETV therapy, especially in patients with higher viral load at week 48 . These inconsistent findings may be due to the more potent antiviral efficacy of TDF than of ETV.

The clinical impact of long-term low-level viremia (HBV DNA < 2,000 IU/mL) in patients with CHB is unclear. In previous observation studies, the risk of developing liver cirrhosis and HCC was not higher in patients with persistent low-level viremia than in those with undetectable HBV DNA [21,22]. However, recently reported studies suggest that persistent low viral load might be 
considered as a risk factor for HCC development, particularly in patients with high level HBsAg or liver cirrhosis [23-25]. With regard to ETV therapy, consistent low viral load is associated with a higher risk of HCC in patients with liver cirrhosis [26]. In our study, two (4.8\%) out of 42 patients with PVR and 14 (7.4\%) out of 190 patients with CVR developed HCC during a median follow-up period of 22 months (range, 6 to 49). This result did not show any clinical impact of persistent low-level viremia on developing HCC in patients receiving TDF therapy. Further prospective studies with larger sample size are required to determine the exact outcomes of long-term TDF treatment.

Tenofovir alafenamide (TAF), a recently developed prodrug of tenofovir, delivers the active ingredient to the hepatocytes more efficiently and requires a lower dose than TDF to achieve a therapeutic concentration in hepatocytes [27]. The long-term TDF therapy results in high systemic exposure to tenofovir, which is related to renal and bone toxicity $[28,29]$. International phase III trials comparing the efficacy and safety of TAF with that of TDF in CHB patients showed that the virologic efficacy was similar between TAF therapy and TDF therapy; however, the ALT normalization, renal and bone safety were in favor of TAF therapy [30]. In these studies, the TDF group showed declines in fasting total cholesterol, low density lipoprotein cholesterol, and high density lipoprotein cholesterol levels while median changes in fasting lipid profiles were small in TAF group [30]. When safety profiles of TDF and TAF are compared, switching to TAF therapy will be a better strategy than continuing TDF in patients with PVR as TDF therapy contributes to renal or bone toxicity.

Our study has some limitations. First, it was a retrospective, single tertiary center study, thus characteristics of patients might be limited. Second, data on other clinical factors affecting VR were insufficient, including genotypes, precore/core promoter mutation, and HBsAg levels. Despite the drawbacks of our study, our results suggest that most patients with PVR to TDF can achieve undetectable HBV DNA during long-term TDF treatment without modification of antiviral therapy.

In conclusion, adaptation of TDF therapy in NAs-naïve patients with PVR at week 48 is unnecessary. TDF therapy in NAs-naïve patients shows excellent viral suppression in real-world practice. Although the time to reach
VR was delayed, prolonged TDF therapy beyond week 48 results in further VR in most patients with PVR, particularly in those with HBV DNA < 100 IU/mL at week 48.

\section{KEY MESSAGE}

1. Continuous tenofovir disoproxil fumarate (TDF) treatment beyond week 48 results in further virologic response in most patients with partial virologic response.

2. There was no significant difference in any liver-related events between patients with and without partial virologic response.

3. Adaptation of TDF therapy in nucleos(t)ide analogues-naïve patients with partial virologic response is unnecessary.

\section{Conflict of interest}

No potential conflict of interest relevant to this article was reported.

\section{Acknowledgments}

The authors thank Sang Gyu Kwak, PhD, Department of Medical Statics, Daegu Catholic University School of Medicine, for his statistical consultation for this study.

\section{REFERENCES}

1. Terrault NA, Lok ASF, McMahon BJ, et al. Update on prevention, diagnosis, and treatment of chronic hepatitis B: AASLD 2018 hepatitis B guidance. Hepatology 2018;67:1560-1599.

2. Korean Association for the Study of the Liver. KASL clinical practice guidelines: management of chronic hepatitis B. Clin Mol Hepatol 2016;22:18-75.

3. Zoulim F, Locarnini S. Management of treatment failure in chronic hepatitis B. J Hepatol 2012;56 Suppl 1:S112-S122.

4. Yuen MF, Sablon E, Hui CK, Yuan HJ, Decraemer H, Lai CL. Factors associated with hepatitis B virus DNA breakthrough in patients receiving prolonged lamivudine therapy. Hepatology 2001;34(4 Pt 1):785-791.

5. Liaw YF, Gane E, Leung N, et al. 2-Year GLOBE trial results: telbivudine is superior to lamivudine in patients 
with chronic hepatitis B. Gastroenterology 2009;136:486495 .

6. Lok AS, McMahon BJ. Chronic hepatitis B: update 2009. Hepatology 2009;50:661-662.

7. European Association for the Study of the Liver. EASL clinical practice guidelines: management of chronic hepatitis B virus infection. J Hepatol 2012;57:167-185.

8. Korean Association for the Study of the Liver. KASL clinical practice guidelines: management of chronic hepatitis B. Clin Mol Hepatol 2012;18:109-162.

9. Zeuzem S, Gane E, Liaw YF, et al. Baseline characteristics and early on-treatment response predict the outcomes of 2 years of telbivudine treatment of chronic hepatitis B. J Hepatol 2009;51:11-20.

10. Liaw YF, Sung JJ, Chow WC, et al. Lamivudine for patients with chronic hepatitis B and advanced liver disease. N Engl J Med 2004;351:1521-1531.

11. European Association for the Study of the Liver; European Association for the Study of the Liver. EASL 2017 clinical practice guidelines on the management of hepatitis $B$ virus infection. J Hepatol 2017;67:370-398.

12. Chang T'T, Gish RG, de Man R, et al. A comparison of entecavir and lamivudine for HBeAg-positive chronic hepatitis B. N Engl J Med 2006;354:1001-1010.

13. Lai CL, Shouval D, Lok AS, et al. Entecavir versus lamivudine for patients with HBeAg-negative chronic hepatitis B. N Engl J Med 2006;354:1011-1020.

14. Zoutendijk R, Reijnders JG, Brown A, et al. Entecavir treatment for chronic hepatitis $\mathrm{B}$ : adaptation is not needed for the majority of naive patients with a partial virological response. Hepatology 2011;54:443-451.

15. Kwon DH, Kim IH, Choung BS, et al. Continuous longterm entecavir therapy in naive chronic hepatitis B patients showing partial virologic response. Gut Liver 2013;7:712-718.

16. Choi HN, Song JE, Lee HC, Jo HH, Lee CH, Kim BS. Efficacy of prolonged entecavir monotherapy in treatment-naive chronic hepatitis B patients exhibiting a partial virologic response to entecavir. Clin Mol Hepatol 2015;21:24-31.

17. Terrault NA, Bzowej NH, Chang KM, et al. AASLD guidelines for treatment of chronic hepatitis B. Hepatology 2016;63:261-283.

18. Ko SY, Choe WH, Kwon SY, et al. Long-term impact of entecavir monotherapy in chronic hepatitis B patients with a partial virologic response to entecavir therapy. Scand J Gastroenterol 2012;47:1362-1367.

19. Lai CL, Gane E, Liaw YF, et al. Telbivudine versus lamivudine in patients with chronic hepatitis B. N Engl J Med 2007;357:2576-2588.

20. Ono A, Suzuki F, Kawamura Y, et al. Long-term continuous entecavir therapy in nucleos(t)ide-naive chronic hepatitis B patients. J Hepatol 2012;57:508-514.

21. Chen CJ, Yang HI, Su J, et al. Risk of hepatocellular carcinoma across a biological gradient of serum hepatitis $B$ virus DNA level. JAMA 2006;295:65-73.

22. Iloeje UH, Yang HI, Su J, et al. Predicting cirrhosis risk based on the level of circulating hepatitis B viral load. Gastroenterology 2006;130:678-686.

23. Sinn DH, Lee J, Goo J, et al. Hepatocellular carcinoma risk in chronic hepatitis $\mathrm{B}$ virus-infected compensated cirrhosis patients with low viral load. Hepatology 2015;62:694-701.

24. Tseng TC, Liu CJ, Yang HC, et al. High levels of hepatitis B surface antigen increase risk of hepatocellular carcinoma in patients with low HBV load. Gastroenterology 2012;142:1140-1149.

25. Kao JH. Risk stratification of HBV infection in Asia-Pacific region. Clin Mol Hepatol 2014;20:223-227.

26. Kim JH, Sinn DH, Kang W, et al. Low-level viremia and the increased risk of hepatocellular carcinoma in patients receiving entecavir treatment. Hepatology 2017;66:335-343.

27. Murakami E, Wang T, Park Y, et al. Implications of efficient hepatic delivery by tenofovir alafenamide (GS-7340) for hepatitis B virus therapy. Antimicrob Agents Chemother 2015;59:3563-3569.

28. Gara N, Zhao X, Collins MT, et al. Renal tubular dysfunction during long-term adefovir or tenofovir therapy in chronic hepatitis B. Aliment Pharmacol Ther 2012;35:13171325.

29. Brown TT, Moser C, Currier JS, et al. Changes in bone mineral density after initiation of antiretroviral treatment with tenofovir disoproxil fumarate/emtricitabine plus atazanavir/ritonavir, darunavir/ritonavir, or raltegravir. J Infect Dis 2015;212:1241-1249.

30. Agarwal K, Brunetto M, Seto WK, et al. 96 Weeks treatment of tenofovir alafenamide vs. tenofovir disoproxil fumarate for hepatitis B virus infection. J Hepatol 2018;68:672-681. 


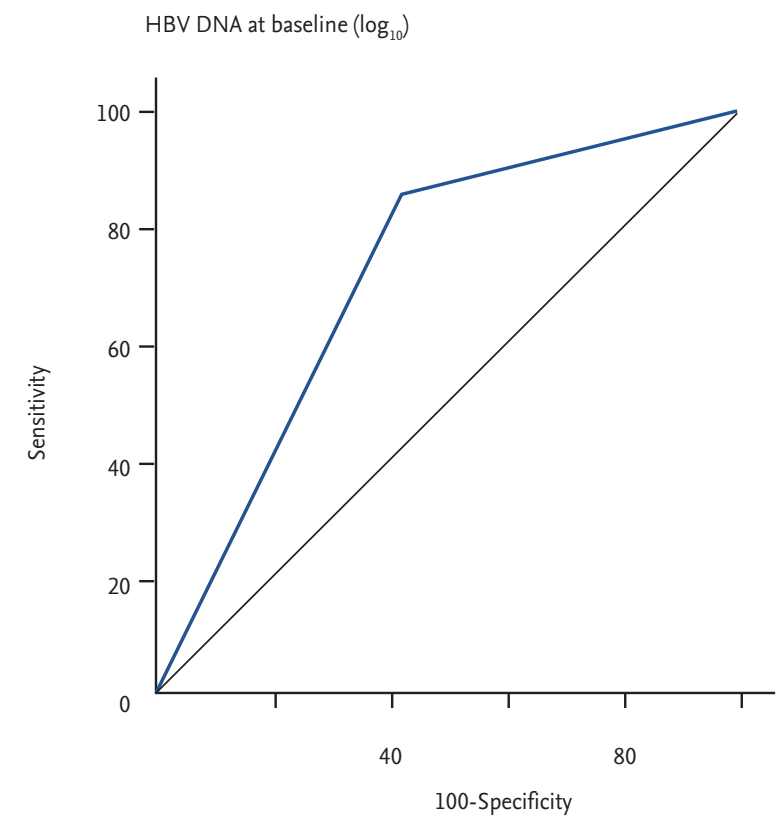

Supplementary Figure 1. Receiver-operating characteristic curves of baseline hepatitis B virus (HBV) DNA level $(\geq 6.34$ $\log _{10} \mathrm{IU} / \mathrm{mL}$ ) predicting partial virologic response. 
HBV DNA at week $12\left(\log _{10}\right)$

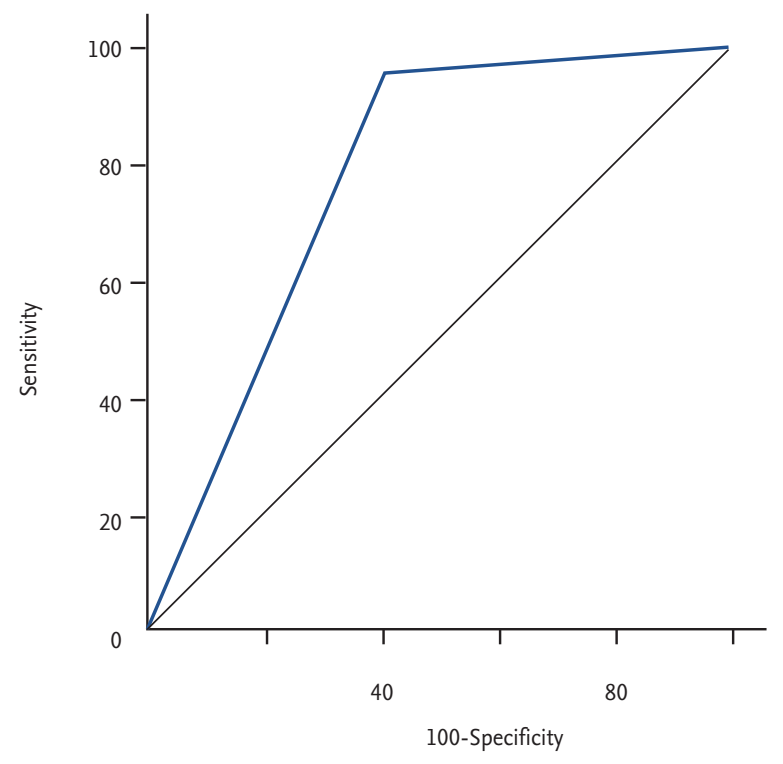

Supplementary Figure 2. Receiver-operating characteristic curves of hepatitis B virus (HBV) DNA level $\left(\geq 1.91 \log _{10}\right.$ $\mathrm{IU} / \mathrm{mL}$ ) at week 12 predicting partial virologic response. 